halb des Striches außerhalb des Tierkörpers befanden. Ganz rechts eine Photographie des uns übersandten Gebildes.

Derartige Vorfälle ereignen sich beim Menschen und mehreren Haustierarten verschiedentlich. Sie stehen bei unseren Haustieren fast ausschließlich mit einer Geburt im Zusammenhang, wobei die Geburtswege weit geöffnet und oft durch Erschöpfung erschlafft sind. In solchen Fällen muß möglichst schnell reponiert werden, wenn die Tiere gerettet werden sollen, widrigenfalls es schnell zu schweren Komplikationen und Blutvergiftungen kommt. Es interessierte uns zunächst deshalb die Frage, ob das Stüds bereits beschlagen gewesen war. Der Einsender hatte ein geschätztes Alter von 2 Jahren angegeben. Auf Grund der grobsinnlichen Veränderungen der Gebärmutterschleimhaut (Karunkeln deutlich erkennbar) und der feingeweblichen Untersuchungen der Gebärmuttergefäße (deutliche Vermehrung von elastischen Fasern in den Ramuli uterini der Arteria uterina media, sog. Graviditätssklerose der Uteruswandgefäße) ist mit Sicherheit anzunehmen, daB das Stück bereits beschlagen gewesen war. Der Vorfall dürfte bei der Geburt passiert sein und bestand somit fast ein halbes Jahr. Für ein solches Alter sprechen auch die erwähnten bindegewebigen Verdickungen und Verschwartungen.

Die beschriebene Erkrankung dürte beim Rehwild außerordentlich selten sein und ist ein Beispiel dafür, mit welch schweren Insulten unser Wild im Gegensatz zu den Haustieren in manchen Füllen fertig werden kann.

\title{
Zusammenfassung
}

Es wird ein teilweiser Gebärmuttervorfall bei einem Mitte Oktober 1959 erlegten, sonst pöllig yesund erscheinenden Reh beschrieben. Der Vorfall muß sich beim Setzen im Frühjahr 1959 sreignet haben.

H. K. ENGLERT

Aus dem Institut für Jagdkunde der Forstlichen Fakultät der Georg-August-Universität Göttingen in Hann. Münden, Direktor: Professor F. Nüßlein

\section{Bösartige Geschwulst des lymphatischen Gewebes beim Hasen}

Ein verendet im Revier gefundener Junghasenrammler aus der Eifel zeigte bei der Sektion einen sehr seltenen Befund. Die Lymphknoten der Brust- und Bauchhöhle und alle Fleischlymphknoten waren bis zu Wallnußgröße verdickt. Ihre Schnittfläche war weich, feucht-speckig und mit mäßig vielen kleinen Blutpunkten durchsetzt. Die Milz war $12,5 \mathrm{~cm}$ lang und $1,8 \mathrm{~cm}$ didk und drehrund. Auf ihrer Schnittfï̈che waren zahlreiche größere grau-weißliche Herde zu sehen (Follikelhyperplasie). Als Todesursache wurde Herzschwächetod mit starkem Lungenödem und Blutstauung im kleinen Kreislauf und Herzmuskeldegeneration ermittelt. Die bakteriologische Untersuchung verlief negativ. Die histologische Untersuchung ergab, daß eine bösartige Geschwulst des lymphatischen Systems, zu dem vornehmlici Milz, Leber und Lymphknoten gehören (lymphatische Leukose), vorlag.

A. VON BRAUNSCHWEIG 